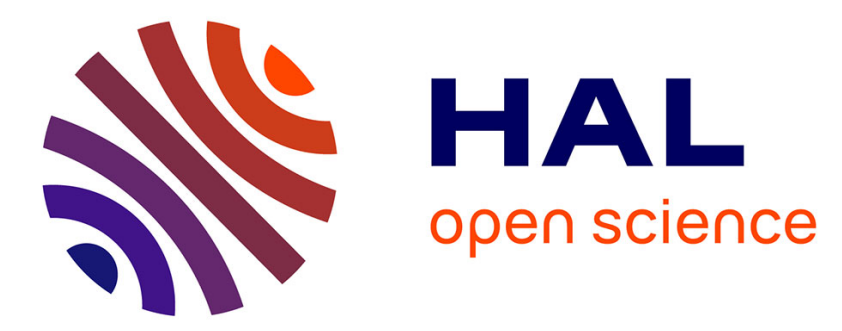

\title{
Polarized Positrons as Spin Detectors for Paramagnetic Centres in Solids
}

Ch. Deckers, J. Ehmann, H. Greif, F. Keuser, W. Knichel, U. Lauff, K. Maier, A. Siegle, M. Tongbhoyai

\section{> To cite this version:}

Ch. Deckers, J. Ehmann, H. Greif, F. Keuser, W. Knichel, et al.. Polarized Positrons as Spin Detectors for Paramagnetic Centres in Solids. Journal de Physique IV Proceedings, 1995, 05 (C1), pp.C1-81-C1-86. 10.1051/jp4:1995109 . jpa-00253545

\section{HAL Id: jpa-00253545 https://hal.science/jpa-00253545}

Submitted on 1 Jan 1995

HAL is a multi-disciplinary open access archive for the deposit and dissemination of scientific research documents, whether they are published or not. The documents may come from teaching and research institutions in France or abroad, or from public or private research centers.
L'archive ouverte pluridisciplinaire HAL, est destinée au dépôt et à la diffusion de documents scientifiques de niveau recherche, publiés ou non, émanant des établissements d'enseignement et de recherche français ou étrangers, des laboratoires publics ou privés. 


\title{
Polarized Positrons as Spin Detectors for Paramagnetic Centres in Solids
}

Ch. Deckers, J. Ehmann*, H. Greif, F. Keuser, W. Knichel, U. Lauff*, K. Maier, A. Siegle**, and $M$. Tongbhoyai

Universität Bonn, Institut für Strahlen- und Kernphysik, Nussallee 14-16, 53115 Bonn, Germany

* Max-Planck-Institut für Metallforschung, Institut für Physik, Heisenbergstrasse 1, 70569 Stuttgart,

Germany

** Universität Stuttgart, Institut für Theoretische und Angewandte Physik, Pfaffenwaldring 57, 70569

Stuttgart, Germany

\begin{abstract}
A technique for studying paramagnetic defects in insulators or semiconductors acting as positron traps is presented. The spin polarization of the paramagnetic electrons of such centres can be determined by investigating the annihilation of spin-polarized positrons, e.g. by Doppler broadening (DB) or positron lifetime measurements. The viability of this technique is demonstrated by measuring the temperature dependence of the polarization of the paramagnetic electrons in $F$ centres in $\mathrm{KCl}$ in high magnetic fields $( \pm 4.5 \mathrm{~T})$.
\end{abstract}

\section{Introduction}

Properties of solids are often determined by defects. Positron annihilation spectroscopy is one of the conventional techniques to investigate vacancy type defects. Using Doppler-broadening or angular correlation measurements these techniques yield only integral information on all different defect types in the sample whereas in positron lifetime spectra usually two or at best three components can be resolved, which correspond e.g. to $\mathrm{e}^{+}$annihilation in vacancies or simall clusters.

Our method is now the combination of DB or lifetime measurements with an additional parameter, namely the polarization of the positrons and electrons. This allows a reliable identification of paramagnetic defects acting as positron traps.

In order to obtain the necessary polarization of $\mathrm{e}^{+}$and $\mathrm{e}^{-}$we made use of two different physical effects. First, the $e^{+}$emitted from a $\beta^{+}$source are longitudinally spin-polarized, with a magnitude of polarization equal to $\mathrm{v} / \mathrm{c}$ [1]. Second, the paramagnetic $e^{-}$in the sample can obtain a considerable degree of spin polarization at low temperatures in a high magnetic field.

The process of annibilation depends on the relative spin orientation of the $\mathrm{e}^{+} \mathrm{e}^{-}$pair. For antiparallel alignment $(s=0)$ the annihilation leads to the emission of two $\gamma\left(\tau_{\text {vac }}=123 p s\right)$. For free $e^{+} e^{-}$-pairs with parallel spin alignment $(s=1)$ only annihilation in three $\gamma$ occurs with a much longer lifetime $\left(\tau_{\text {vac }}=140 \mathrm{~ns}\right)$. In solids the lifetime of the $\mathrm{e}^{+} \mathrm{e}^{-}$pairs with $\mathrm{s}=1$ is reduced by the so called "pick-off"-process, where the $\mathrm{e}^{+}$ annihilates with an $e^{-}$with antiparallel spin orientation bound to a neighbour atom and therefore undergoes a $2 \gamma$-decay. In general, this "pick-off"-annihilation shows a large Doppler broadening of the $511 \mathrm{keV} \gamma$-line. 
By measurement of the Doppler broadening or the positron lifetime as a function of the extemal magnetic field one can therefore clearly distinguish between these two annihilation modes.

This means that polarized $\mathrm{e}^{+}$can be used to detect the spin polarization of electrons in paramagnetic $\mathrm{e}^{+}$ trapping centres.

Earlier angular correlation measurements have shown that polarized positrons can be used for researchs in ferromagnetic metalls. [2-5]

The combination of the electron spin sensitive positron annihilation with EPR spectroscopy clearly implies a great potential for future progress in the identification of different defect types. For our first demonstration of the efficiency of this new method we have chosen the F-centres in $\mathrm{KCl}$ since this system has been studied by $\mathrm{e}^{+}$annihilation [6-12] and its paramagnetic properties are well known [13].

\section{Experimental}

As a sample we used a $\mathrm{KCl}$ crystal of $8 \mathrm{~mm}$ in diameter and approximately $1 \mathrm{~mm}$ in height. The crystal was coloured by annealing in a stainless-steel tube for $75 \mathrm{~min}$ at $970 \mathrm{~K}$ in potassium vapour under equilibrium pressure and subsequently cooled rapidly to room temperature. This procedure yielded a F-centre concentration in the order of $10^{18} \mathrm{~cm}^{-3}$ [13].

The external magnetic field of $4.5 \mathrm{~T}$ was generated by the superconducting split-coil magnet of the 12detector IPAC spectrometer at the Institut für Strahlen- und Kernphysik of the University of Bonn which is described in detail elsewhere [14].

Temperatures down to $1.2 \mathrm{~K}$ were produced with a simple ${ }^{4} \mathrm{He}$-evaporation cryostat placed in the bore of the split-coil magnet. The temperature was measured with a calibrated carbon-glass resistor and controlled with an accuracy better than $\pm 0.1 \mathrm{~K}$.

Fig. 1 shows the experimental set up for the Doppler-broadening measurement. We used a ${ }^{68} \mathrm{Ge} /{ }^{68} \mathrm{Ga}{ }^{+}$ source $(40 \mu \mathrm{Ci})$ with a maximum $\mathrm{e}^{+}$-energy of $1.9 \mathrm{MeV}$. For the lifetime measurement a ${ }^{22} \mathrm{Na}(10 \mu \mathrm{Ci})$ source was put on an $\mathrm{Al}$ backing in order to absorb the $\mathrm{e}^{+}$emitted backwards (fig. 2).

To enhance the effective $\mathrm{e}^{+}$-polarization for the lifetime measurement we covered the ${ }^{22} \mathrm{Na}$ source with $100 \mu \mathrm{m}$ annealed Al. We calculated an average $\mathrm{e}^{+}$-polarization of $\mathrm{P}_{\mathrm{z}}=0.46$ for the Doppler and $P_{z}=0.37$ for the lifetime measurement.

For the Doppler measurement the Ge-detector worked in coincidence with a BGO-scintillator in order to suppress Compton scattering at the collimator. The electronic stability was monitored with the $482 \mathrm{keV} \gamma-$ line of a ${ }^{181} \mathrm{Hf}$-source.

The lifetime was measured with $8 \mathrm{BaF}_{2}$ detectors $\left(\varnothing 44 \mathrm{~mm}^{*} 84 \mathrm{~mm}\right)$ with a time resolution of $650 \mathrm{ps}$ [15].

We analysed the Doppler broadening in terms of the lineshape parameter $S$. In each coincidence spectrum more than $7 * 10^{5}$ events were registered. The lifetime spectra were analysed in terms of the lifetime parameter $R$. $[15,16]$ This parameter is defined as the ratio of the numbers of the annihilations with the long lifetime component to the total number of annihilations. With this parameter we discriminated between the annihilation in the aluminium and that in the $\mathrm{F}$-centres $\left(\tau_{\mathrm{Al}}=166 \mathrm{ps}<<\tau_{\mathrm{KCl}, \mathrm{F}} \approx 900 \mathrm{ps}\right)$. 


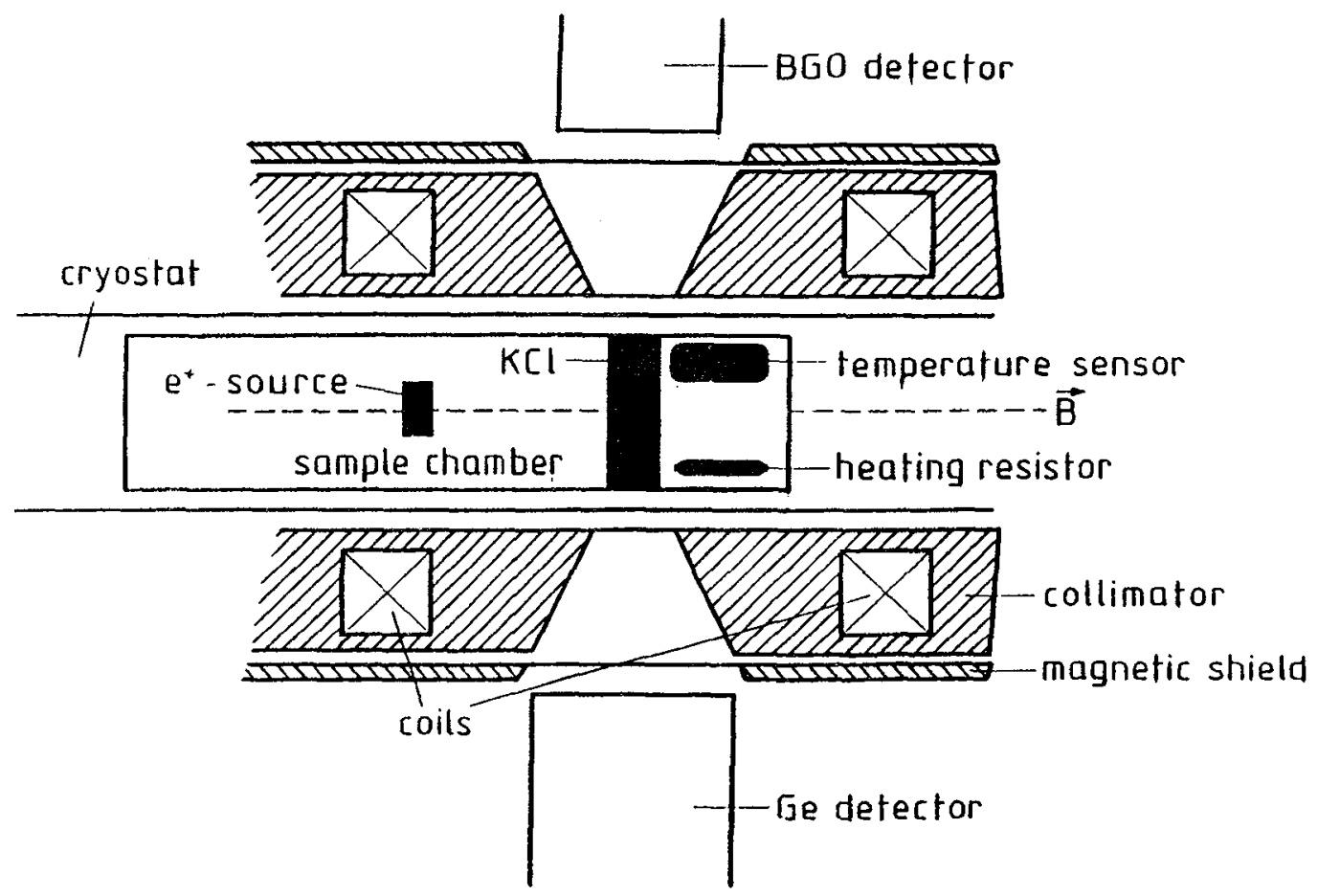

Fig. 1 Experimental setup for the measurement of the Doppler broadening of the $2 \gamma$-annihilation. The Gedetector operates in coincidence with a BGO-detector. The dashed line indicates the axis of the external field.

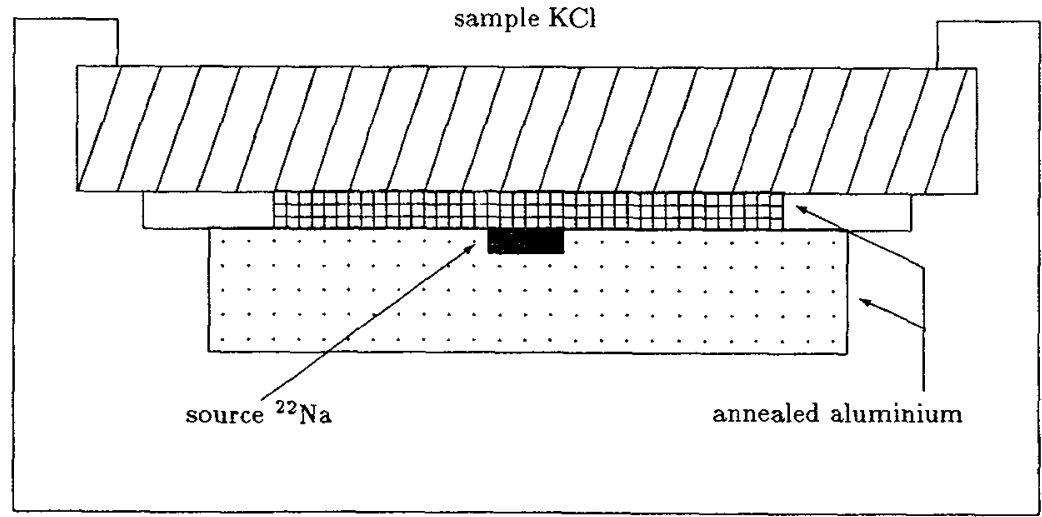

Fig. 2 Schematic view of the source/specimen geometry for the lifetime measurement. Backwards emitted positrons annihilate in the annealed aluminium with a short lifetime $\left(\tau_{\mathrm{Al}}=166 \mathrm{ps}<<\tau_{\mathrm{KCl}, \mathrm{F}} \approx 900 \mathrm{ps}\right)$ 


\section{Results and discussion}

\subsection{Doppler-broadening measurement}

Fig. 3 shows the temperature dependence of the lineshape parameter $S$ for both orientations of the external magnetic field. The distinct difference in the parameter for the two orientations increases with decreasing temperature in the same way as the $\mathrm{e}^{-}$-polarization. We attribute this to the increase of the $e^{-}$-polarization in the paramagnetic defects. This conclusion is supported by the following facts: In our sample (F-centre concentration $\approx 10^{18} \mathrm{~cm}^{-3}$ ) almost every $\mathrm{e}^{+}$is trapped in such a defect [6]. Magnetic quenching experiments $[11,12]$ indicate the formation of positronium-like states in coloured $\mathrm{KCl}$. The $\mathrm{s}=1$ state was observed by a narrow annihilation line in an angular correlation experiment [6] and by a long lifetime component [7]. This quasi-positronium [17] is thought to be located in the F-centre; its formation therefore involves the paramagnetic $\mathrm{e}^{-}$of these centres, whose wavefunctions are known from EPR experiments to be concentrated near the vacant anion sites.

The measured temperature dependence of the $S$ parameter is in excellent agreement with a simple theory of electron polarization given by $P\left(e^{-}\right)=\tanh \left(\mu_{B} B / k_{B} T\right)$. We consider this as a strong evidence that the temperature dependence of the Doppler broadening is due to temperature dependence of the spin polarization of the electrons in the F-centres.

\subsection{Lifetime measurement}

In fig.4 the lifetime parameter $\mathrm{R}$ and the corresponding theoretical expression for the temperature dependence of the e-polarization are shown. Obviously there is also a good agreement of the data with this simple theory for both magnetic field orientations .

Without an external magnetic field the absolute value of the lifetime parameter $R$ shows no temperature dependence. Its larger value can be explained with the magnetic quenching in the F-centres $[11,12]$. In addition we observed no temperature dependence because of the absence of the electron polarization in the F-centres. In addition the lifetime parameter $\mathrm{R}$ in the pure crystal shows no magnetic field dependence.

Therefore we can simply derive the polarization of the paramagnetic $\mathrm{e}^{-}$as a function of temperature from the fit to the semi-empirical expression. The magnitude of the spin-polarization of the paramagnetic $\mathrm{e}^{-}$is indicated on the right-hand abscissa of fig. 3 .

Summing up one can say that on account of our measurements polarized positrons are actually established as spin detectors for paramagnetic electrons. In the near future it will be necessary to apply our method for the investigation of other paramagnetic defects acting as $\mathrm{e}^{+}$traps in semiconductors [8-10] and insulators $[6,7,11,12]$. With the variable energy $\mathrm{e}^{+}$-beam at our laboratory [18] it will also be possible to detect paramagnetic states at surfaces and in regions near to the surface and thus to measure depth-resolved profiles of paramagnetic defects. 


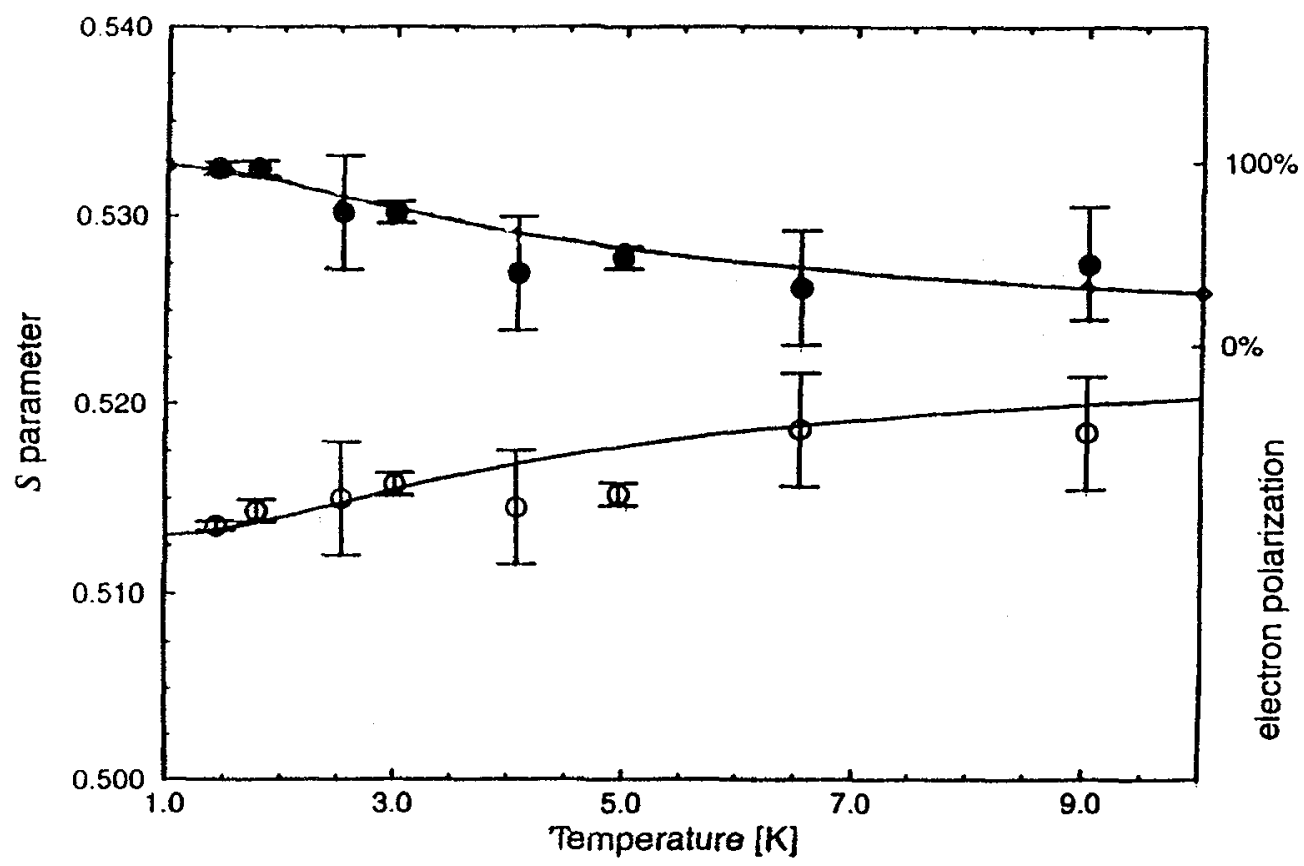

Fig. 3 Temperature dependence of the lineshape parameter $\mathrm{S}$ in coloured $\mathrm{KCl}$ measured with polarized positrons. The magnetic field is parallel $(\bullet)$ or antiparallel $(0)$ to the positron polarization. The solid lines represent a fit to expression $S(T) \propto \tanh \left(\mu_{B} B / k_{B} T\right)$.

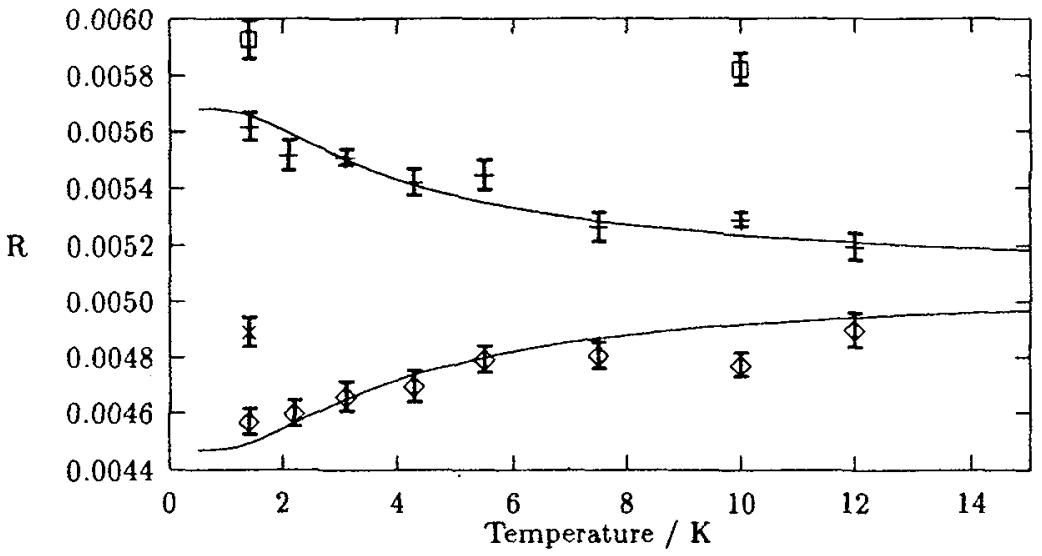

Fig. 4 Temperature dependence of the lifetime parameter $\mathrm{R}$ in coloured $\mathrm{KCl}$. The magnetic field is parallel $(\diamond)$ or antiparallel $(-)$ to the positron polarization $[(\square)$ zero magnetic field and $(x)$ uncoloured $\mathrm{KCl}$ crystal]. The solid lines represent the tanh-temperature dependence of the electron polarisation. 


\section{References}

[1] K. Siegbahn, ed., Alpha-,beta- and gamma-ray spectroscopy (North-Holland, Amsterdam, 1965)

[2] S.S. Hanna, R.S. Preston, Phys. Rev. 106 (1957) 1363

[3] S. Berko, J. Zuckermann, Phys. Rev. Letters 13 (1964) 339a

[4] S. Berko, J. Zuckermann, Phys. Rev. Letters 14 (1965) 89

[5] K.E.H.M. Hansen, P.E. Mijnarends, L.P.L.M. Rabou, K.H.J. Busdow, Phys. Rev. B42 (1990) 1533

[6] D. Herlach and F. Heinrich, Phys.Lett.A 31 (1970) 47

[7] A. Dupasquier, Lett. Nuovo Cimento 4 (1970) 13

[8] S. Dannefaer in Defect control in semiconductors, ed. K. Sumino (North Holland, Amsterdam, 1990) p. 1561

[9] R Krause, U. Beyer, Th. Drost, A. Polity, H. Leipner, M. Brohl and H. Alexander, Mater. Sci. Forum 105-110 (1992) 1101

[10] K. Saarinen, S. Kuisma, P. Hautojärvi, C. Corbel and C. LeBerre, Phys. Rev. Lett. 70 (1993) 2794

[11] D. Herlach and F. Heinrich, Helv. Phys. Acta 43 (1970) 489

[12] A. Bisi, A. Dupasquier and L. Zappa, J. Phys. C4 (1971) L33

[13] J.H. Schulman and W.D. Compton, Colour centers in solids (Pergamon, Oxford, 1962)

[14] I. Alfter, E. Bodenstedt, B. Hamer, J. van den Hoff, W. Knichel, H. Münning, S. Piel, J. Schüth and R. Sajok, Nucl. Instr. Methods A 321 (1992) 506

[15] Ch. Deckers, Diplomarbeit, Universität Bonn, 1994

[16] M. Bertolaccini, A. Bisi, G. Gambarini, L. Zappa, J.Phys. C Vol. 7 (1974) 3827

[17] A. Dupasquier, in Positrons in solids, ed. P. Hautojärvi (Springer, Berlin 1979) p. 197

[18] H. Greif, Diplomarbeit, Universität Bonn, 1994 